\title{
Obesity and Metabolic Comorbidity in Bipolar Disorder: Do Patients on Lithium Comprise A Subgroup? A Naturalistic Study.
}

Jake Prillo ( $\square$ jake.prillo@mail.mcgill.ca )

McGill University https://orcid.org/0000-0002-5398-8003

Jocelyn Fotso Soh

McGill University

Annemick Dols

GGZ inGeest/VUmc

Haley Park

McGill University https://orcid.org/0000-0002-7469-2498

Serge Beaulieu

McGill University Department of Psychiatry

Outi Linnaranta

McGill University Department of Psychiatry

Soham Rej

McGill University

Research

Keywords: obesity, metabolic syndrome, lithium, bipolar disorder, medical comorbidity

Posted Date: October 27th, 2020

DOI: https://doi.org/10.21203/rs.3.rs-95636/v1

License: (c) (i) This work is licensed under a Creative Commons Attribution 4.0 International License.

Read Full License 
Word Count: 2587

Abstract: 250

Tables: 2

Figures: 0

Supplemental Tables: 0

References: 33

\title{
Obesity and metabolic comorbidity in bipolar disorder:
}

Do patients on lithium comprise a subgroup? A naturalistic study.

\author{
Jake Prillo, MDCM ${ }^{1 *}$ \\ Jocelyn Fotso Soh, $\mathrm{MSc}^{1}{ }^{*}$ \\ Annemiek Dols M.D., Ph.D. ${ }^{3}$ \\ Haley Park BSc ${ }^{1}$ \\ Serge Beaulieu M.D., Ph.D. ${ }^{2}$ \\ Outi Linnaranta M.D., Ph.D. ${ }^{2 * *}$ \\ Soham Rej, MD, $\mathrm{MSc}^{1 * *}$
}

1. GeriPARTy Group, Division of Geriatric Psychiatry, Jewish General Hospital, McGill University, Montreal, Canada

2. Douglas Mental Health University Institute and Department of Psychiatry, McGill University, Montreal, Canada.

3. Department of Old Age Psychiatry, GGZ inGeest/VUmc, Amsterdam, the Netherlands:

* denotes shared first-authorship

**denotes shared last-authorship

Correspondence: Jake Prillo, MDCM, Geri-PARTy Research Group, Jewish General Hospital/Lady Davis Institute, McGill University, 4333 Cote Ste-Catherine, Montreal, QC, H3T, 1E4, Montreal, Canada, email: jake.prillo@ mail.mcgill.ca

Running Head: Obesity \& Metabolic Comorbidity in Bipolar 


\begin{abstract}
Background: Bipolar disorders (BD) are associated with increased prevalence of obesity and metabolic syndrome (MetS). Nevertheless, there is a wide range in prevalence estimates, and little is known about the relative contributions of medications, especially lithium. We hypothesized that lithium use is not associated with increased body mass index (BMI), metabolic syndrome, and type II diabetes (DM II), when compared to nonlithium users (those on anticonvulsants (ACs) or second-generation antipsychotics (APs)).
\end{abstract}

Methods: Cross-sectional study of 129 patients aged 18-85 with bipolar disorder, followed at tertiary care clinics in Montreal. Patients using lithium were compared with those not on lithium, for body mass index and metabolic syndrome.

Results: The prevalence of obesity and MetS in the sample of lithium-using bipolar patients was $42.4 \%$ and $34.9 \%$, respectively, with an average BMI of $29.10(+/-6.70)$. Lithium and non-lithium groups did not differ in BMI or prevalence of MetS. However, compared to the non-lithium group, lithium users had lower hemoglobin A1C (5.24 +/0.53 versus $6.01+/-1.83, \mathrm{U}=753.5, \mathrm{p}=0.006)$ and lower triglycerides $(1.46+/-0.88$ versus $2.01+/-1.25, \mathrm{U}=947, \mathrm{p}=0.020)$.

Conclusions: There is a high prevalence of obesity and metabolic syndrome among bipolar disorder patients. However, this did not appear to be associated with lithium use, 
when compared to those not on lithium. The lithium subgroup was also associated with lower prevalence of type II diabetes. Future prospective and intervention studies with larger sample sizes are necessary to further explore the association between lithium and insulin resistance, as well as its underlying mechanisms.

Key words: obesity; metabolic syndrome; lithium; bipolar disorder; medical comorbidity

\section{Abstract Word Count: 250}

Keywords: metabolic syndrome, obesity, lithium, insulin resistance 


\section{INTRODUCTION}

Lithium remains a first-line therapy in bipolar disorder, with indications in acute

4 mania, depression, and maintenance treatment ${ }^{1}$. Additionally, it is associated with unique

5 anti-suicidal properties ${ }^{2}$. Despite this, lithium is often avoided for its adverse physical

6 effects including reduced renal function, hypothyroidism, and hyperparathyroidism ${ }^{3}$.

7 Lithium is also avoided for weight gain, though alternatives (especially SGAs quetiapine

8 and olanzapine) are thought to be more detrimental in this regard ${ }^{4,5}$.

10 Among these adverse physical effects, weight gain is especially concerning, as it

11 can lead to obesity. Obesity is a constituent of metabolic syndrome, a constellation of risk

12 factors notably associated with cardiovascular disease and stroke ${ }^{6}$. Weight gain is further

13 recognized in the literature as contributing to poor physical health and early mortality ${ }^{7}$,

14 treatment non-adherence ${ }^{8}$, worsening psychiatric outcomes ${ }^{9}$, and elevated economic

$15 \operatorname{costs}^{10}$. Mitigating obesity is highlighted in numerous consensus guidelines ${ }^{1,11}$, which

16 state that body mass index, diabetes, and dyslipidemia be assessed at treatment baseline

17 and then regular intervals thereafter.

19 While it is known that patients with a bipolar disorder are at an increased risk of

20 obesity $^{12}$, prevalence rates remain heterogeneous. Estimates range from $20-65 \%$ of

21 patients with a bipolar disorder ${ }^{13}$. The same is true for metabolic syndrome, including

22 waist circumference, diabetes, and dyslipidemia. Further, the relative contributions of the

23 bipolar illness itself, aging, and mood-stabilizing medications (such as lithium) remain to 
24 be clarified. A number of randomized clinical trials (RCTs) and cohort studies suggest

25 that lithium causes less weight gain ${ }^{4,5,14-16}$. However, in these studies, BMI and metabolic

26 effects are not reported as primary outcomes. These trials also include strict 'treatment

27 arms' that do not reflect true clinical prescribing patterns (for example, medication

28 combinations, augmentation, and polypharmacy).

30 The purpose of this study is to 1) estimate the prevalence of obesity and MetS

31 amongst a cross-sectional sample of bipolar disorder patients. We will also 2) examine

32 the prevalence of constituents of MetS, including BMI, waist circumference,

33 hypertension, lipid profile, and diabetic screening tests. Finally, we will 3) assess whether

34 there are any differences in these measures between lithium and non-lithium BD patients.

35 We hypothesize that lithium users will have less medical comorbidity, including obesity,

36 metabolic syndrome, and diabetes.

\section{MATERIALS and METHODS}

40 We combined data from two studies that examined physical comorbidity in

41 bipolar patients. We have provided individual descriptions of the methods of each study

42 below. Specific inclusion or exclusion criteria of the studies have been previously 43 reported $^{17,18}$. 
47 controlled RCT at three tertiary mental health sites in Montreal, Québec: Douglas Mental

48 University Institute (DMHUI), Jewish General Hospital (JGH), and McGill University

49 Health Centre (MUHC). Patients were lithium users aged 18-85, with any psychiatric

50 disorder. At baseline, patients' self reported demographic information, past medical and

51 psychiatric history, and somatic complaints. Current medication was obtained from

52 medical charts and confirmed by the patient. At each visit (baseline, 4-weeks, 12-weeks),

53 psychiatric symptoms were measured using the Montgomery-Asberg Depression Scale

54 (MADRS) $^{19}$ and Young Mania Rating Scale (YMRS) ${ }^{20}$. Finally, physical measures (BMI

55 and waist circumference), serum cholesterol levels, serum glucose levels, and thyroid

56 function were also measured at each visit. For this analysis, baseline data from Study 1

57 was used from patients with bipolar disorder $(n=43)$.

Study 2 examined the relationship between mood, sleep, and food intake in

60 bipolar patients. Patients were recruited from those presenting at the Bipolar Disorders

61 clinic at the DMHUI. This is a specialized clinic where the diagnosis of patients has been

62 systematically evaluated and scrutinized before acceptance. Patients were 18 years or

63 older and were receiving care exclusively as outpatients. Medication, demographic,

64 clinical, and laboratory information, including serum cholesterol, serum glucose, and

65 thyroid function, were retrieved for the initial visit. Two in-person visits, two weeks

66 apart, were used to evaluate physical measures and mood. For this analysis, baseline data

67 from Study 2 was used $(n=86)$.

68

69 Exposures - Lithium Users and Non-Users: 
We classified bipolar disorder patients into current lithium users or non-users.

71 This was achieved by a chart review of any prescriptions valid within a 2-week period

72 before or after the initial baseline visit.

73

74 Primary Outcome:

75 Our primary outcome is obesity, measured via BMI. Obesity was chosen as

76 lithium and other mood stabilizers have frequently been associated with weight gain,

77 which may lead to treatment non-adherence and metabolic complications. It is also a

78 value that can be easily measured and trended, no matter the healthcare setting. BMI was

79 calculated using a standard formula: $\mathrm{BMI}=$ weight $(\mathrm{kg}) /$ height $^{2}$ (meters). A BMI $\geq 30$

80 was taken to indicate obesity, according to the National Institute of Health (NIH).

\section{Secondary Outcomes:}

83 Our secondary outcomes are average BMI, BMI classes, metabolic syndrome, and

84 hemoglobin A1c. The BMI classes designated by the NIH are: BMI $<19.0$

85 (underweight), BMI 19-24.9 (normal), BMI 25.0 - 29.9 (overweight), BMI 30.0-34.9

86 (class I obesity), BMI 35.0+ (class II \& III obesity).

88 Metabolic syndrome was diagnosed in patients who fulfilled three or more of the

89 five criteria based on the National Cholesterol Education Program Treatment Panel III

90 (NCEP III) criteria: 1) Abdominal obesity: waist circumference $\geq 102 \mathrm{~cm}$ for men and $\geq$

$9188 \mathrm{~cm}$ for women. Waist circumference was measured in two ways: at the top of the iliac

92 crest as per the National Institutes of Health (NIH), and midway between the last palpable 
93 rib and the top of the iliac crest according to World Health Organization (WHO)

94 standards; 2) Glucose dysmetabolism: impaired fasting plasma glucose (5.5-6.9mmol/L)

95 or diabetes (fasting plasma glucose $\geq 7 \mathrm{mmol} / \mathrm{L} ; 3$ ) Dyslipidemia: elevated plasma

96 triglyceride ( $\geq 1.7 \mathrm{mmol} / \mathrm{L})$; 4) Dyslipidemia (second, separate criteria): decreased high-

97 density lipoprotein (HDL) (<1.03mmol/L for men and $<1.30 \mathrm{mmol} / \mathrm{L}$ for women); and 5)

98 Hypertension. Hypertension was defined as high blood pressure on patients' self-reported

99 medical history or indication of pharmacologic intervention according to a medication

100 report.

101

102 Hemoglobin A1c is the most widely used clinical test to diagnose diabetes,

103 indicating the mean glucose concentration over 120 days, although it is not traditionally

104 used in the diagnosis of metabolic syndrome.

105

106

Exploratory Outcomes:

107 Our exploratory outcomes were the constituents of MetS: abdominal obesity,

108 glucose dysmetabolism, dyslipidemia: elevated plasma triglyceride, dyslipidemia:

109 decreased high-density lipoprotein, and hypertension. Additionally, we examined thyroid

110 function, as it is a frequent adverse event during lithium use. Hypothyroidism was

111 characterized as a TSH $>5.0 \mathrm{mIU} / \mathrm{L}$ or necessitating thyroid hormone replacement.

112

\section{Statistical Analysis:}

114 Data was initially assessed for normality using the Shapiro-Wilk test. We

115 compared the exposure groups for demographic values, as well as for primary, secondary, 
116 and exploratory outcomes. We used Mann-Whitney U tests to examine continuous

117 variables for non-normal distributions. Chi-squared tests were employed for dichotomous

118 variables (eg. Diabetes Yes/No). A two-tailed alpha of 0.05 was used to determine

119 statistical significance and all analyses were performed using IBM SPSS 26.0 (IBM SPSS

120 Inc, Chicago, IL, USA).

121

122 RESULTS

123

124 In total, 129 bipolar disorder patients were included in the analysis of this study.

125 Of these, 66 were lithium users and 63 were non-users. The lithium group was $43.9 \%$

126 male, and the mean age was $49.1( \pm 11.78)$. The majority $(n=50,79.4 \%)$ of lithium users

127 had an age of onset of psychiatric symptoms $<30$ years of age, with an average of more

128 than four mood episodes in the course of their illness.

130 Table 1 summarizes the study participants' baseline demographic and clinical

131 characteristics. The lithium and non-lithium groups differed significantly in their age of

132 onset $\left(\mathrm{p}=0.017, \mathrm{x}^{2}=13.8\right)$ number of mood episodes $\left(\mathrm{p}=0.001, \mathrm{x}^{2}=15.9\right)$, and their

133 baseline MADRS ( $4.30 \pm 4.62$ versus $6.81 \pm 6.93$ respectively) and YMRS scores (4.42 \pm

1348.03 versus $15.90 \pm 12.80$ respectively). There were higher standardized scores for

135 depression and mania in the non-lithium group. Additionally, there were significant

136 differences in the patients' medication profiles. Intuitively, a higher proportion of non-

137 lithium users were on antipsychotic medications and anticonvulsants, as well as

138 antidepressants. More specifically, 76.2\% of non-lithium users were on antipsychotics, 
139 compared to only $58.7 \%$ of lithium users $\left(\mathrm{p}=0.036, \mathrm{x}^{2}=4.375\right)$. This pattern continued

140 for anticonvulsants (82.5\% of non-lithium users, versus $36.5 \%)$ and antidepressants

141 (57.1\% for non-lithium users, versus $38.1 \%)$. In terms of somatic medications, patients in

142 the non-lithium group were also on more medications for diabetes and dyslipidemia.

144 Table 2 summarizes obesity, BMI and other physical health outcome data. With

145 respect to the primary outcome, $43.94 \%$ of lithium using and $34.92 \%$ of non-lithium

146 bipolar patients had obesity. There was no statistically significant difference in rate of

147 obesity between these groups $\left(\mathrm{p}=0.384, \mathrm{x}^{2}=0.758\right)$.

149 For secondary outcomes, mean BMIs were on the cusp of overweight and class I

150 obesity; average BMI of the lithium-using patients was $29.10( \pm 6.70) \mathrm{kg} / \mathrm{m}^{2}$, and non-

151 lithium users $30.20(+/-8.57) \mathrm{kg} / \mathrm{m}^{2}$. There was no statistically significant difference in

152 BMI between the two groups. The vast majority of the 66 lithium-using patients were

153 outside of the normal BMI range: $27.3 \%$ were overweight, $25.8 \%$ had class I obesity, and

$15416.7 \%$ class II \& III obesity. The prevalence of metabolic syndrome in lithium users was

$15535.7 \%$. There was no significant difference between lithium users and non-lithium users

156 in BMI classes or prevalence of metabolic syndrome. However, there was a statistically

157 significant difference in glucose metabolism as measured by HbA1C. Lithium use was

158 associated with lower HbA1c overall ( $\mathrm{p}=0.006, \mathrm{U}=753.5)$.

159

160 Lastly, for exploratory outcomes, lithium use was associated with abnormal levels

161 of triglycerides, with lower levels than non-lithium users $(p=0.020, U=947)$. There was 
162 no difference in the remaining constituents of metabolic syndrome, including waist

163 circumference, fasting plasma glucose or diabetes, cholesterol profile or dyslipidemia, or

164 hypertension. There was also no difference in thyroid function, despite lithium's well-

165 established association with hypothyroidism.

167 DISCUSSION

169 We present a sample of patients with a bipolar disorder in a tertiary care,

170 naturalistic setting, where polypharmacy is common. Overall, the prevalence of obesity

171 and metabolic syndrome in this sample of 129 bipolar patients is $44 \%$ and $35 \%$

172 respectively. There was no statistically significant difference in prevalence of obesity in

173 lithium and non-lithium BD patients. This was also true for secondary outcomes,

174 including average BMI, BMI classes, and metabolic syndrome, as well as exploratory

175 outcomes, such as waist circumference, fasting glucose and diabetes, impaired lipids and

176 dyslipidemia, hypertension, and hypothyroidism. However, the most interesting finding is

177 that the groups differed in the markers of insulin resistance, $\mathrm{HbA1C}$ and triglycerides.

178 Despite polypharmacy, patients on lithium had a lower level of insulin resistance.

180 In other words, our findings largely indicate similar physical and metabolic

181 comorbidity between lithium-using and non-lithium bipolar patients. This offers

182 important insight into the adverse effects of 'real-life' bipolar pharmacotherapy

183 treatment. In this analysis, the majority of patients were treated with conventional mood

184 stabilizers, lithium or valproate, combined with various antidepressants and second- 
185 generation antipsychotics. These medications have been studied and compared more

186 extensively as monotherapy; for example, lithium has previously been reported to cause

187 more clinically significant weight gain than valproate, but less than quetiapine ${ }^{14,16}$.

188 However, the research is largely mixed regarding weight gain and other side effects (ie.

189 metabolic syndrome and its constituents) of pharmacotherapy combinations. Previous

190 studies are limited by their focus on individual antipsychotics or mood stabilizers and

191 modest sample sizes ${ }^{21}$. Overall, the present study seems to suggest that lithium and non-

192 lithium combinations emerge as comparable.

194 Interestingly, we found lithium use to be associated with lower markers of insulin

195 resistance, as measured by HbA1c and triglycerides respectively. This fits into a larger

196 discussion in the literature that conceptualizes bipolar disorder as being comprised of

197 multiple subgroups, such as lithium-responders. One interpretation of this finding is that

198 lithium-responders, even prior to lithium exposure, represent a subgroup that is naturally

199 less predisposed to insulin resistance. However, a recent retrospective study has found the

200 inverse to be true: comorbid bipolar disorder and insulin resistance appears to be

201 associated with more severe clinical features and poor response to lithium ${ }^{22,23}$. This

202 association can potentially be explained by shared pathophysiological mechanisms

203 between bipolar disorder and glucose dysregulation, including genetic and epigenetic

204 links, mitochondrial dysfunction, and hypothalamic-pituitary-adrenal axis alterations ${ }^{24}$. In

205 particular, glycogen synthase kinase-3 beta (GSK-3b), an essential kinase involved in cell

206 metabolism and survival, has been identified as having significant effects on neuronal

207 plasticity in bipolar disorder patients. It may also suppress two important targets of 
208 insulin action, glycogen synthase and insulin receptor substrate- $1^{25}$. Lithium, moreso than

209 other mood stabilizers such valproate, appears to act as an inhibitor of the GSK-3b

210 enzyme. Therefore, a second and competing hypothesis that lithium itself modulates both

211 affective and dysmetabolic disorders ${ }^{26}$. Sleep deprivation can rapidly result in insulin

212 resistance, and while in general patients with a bipolar disorder have disrupted circadian

213 rhythms, lithium seems to be more likely to regulate the rhythms ${ }^{27}$. In sum, these

214 pathophysiological explanations are consistent with our results in lithium-responsive

215 bipolar patients, who experienced lower levels of glycosylated hemoglobin and

216 triglycerides.

218 From a population health perspective, our findings contribute to a growing

219 understanding about metabolic comorbidities in severe mental illness. The prevalence of

220 obesity in this bipolar study group was almost double that of the general Canadian adult

221 population $(42.3 \% \text { versus } 24.1 \%)^{28}$, and almost triple that of the general Québecois adult

222 population $(42.3 \% \text { versus } 16.4 \%)^{29}$. The same can be said about metabolic syndrome

$223(35.7 \% \text { versus } 19.1 \%)^{30}$. This confirms previous findings that obesity is startlingly

224 common in bipolar patients and necessitates urgent attention. Prevention and early

225 intervention with lifestyle interventions and pharmacological options is recommended ${ }^{31}$.

226 Further, the high concurrence between psychiatric and medical comorbidity argues for

227 primary care models that allow an integrated treatment approach to optimize outcomes. 228

229 Strengths and limitations: 
This study has several strengths. To begin, the study design is representative of

231 the "real-world": it had the enrolment of both bipolar I and II patients, enrolment of

232 patients of all ages, and the inclusion of patients with concomitant psychiatric diagnoses

233 (eg. personality disorder, substance use). The findings can be generalized to tertiary care

234 bipolar outpatients. The grand majority of patients were based at the same hospital and so

235 their lab tests were processed by the same laboratory. Additionally, the sample size was

236 comparable or larger than many existing studies.

238 We recognize some limitations of our study. The largest limitation is that the

239 study design was cross-sectional, which makes causation difficult to infer. Furthermore,

240 body mass index, the basis of the primary outcome, is frequently criticized in the

241 literature for its true clinical relevance as it has arbitrarily defined categories, does not

242 differentiate between fat and muscle mass ${ }^{32}$, and has been paradoxically associated with

243 lower mortality ${ }^{33}$, although the inclusion as waist circumference as a surrogate for obesity

244 helps to mitigate this. Further, there was an important reliance on self-reported data for

245 hypertension. Future studies could (a) incorporate a larger number of patients in a

246 prospective study design to improve statistical power and better quantify effects of

247 lithium (and other mood stabilizers) on metabolic outcome, (b) examine combination

248 treatments more exhaustively, and (c) explore the postulated pathophysiological

249 mechanisms linking bipolar disorders and metabolic dysregulation.

\section{CONCLUSION}


254 There is a higher prevalence of obesity and metabolic syndrome in this sample of

255 bipolar disorder patients, when compared to the general population. However, prevalence

256 of obesity and metabolic syndrome within bipolar disorder patients did not appear to be

257 associated with lithium use, when compared to non-lithium users (e.g. those on

258 anticonvulsants, second-generation antipsychotics). Constituents of metabolic syndrome

259 also did not significantly differ between lithium users vs. non-users. An important

260 exception was insulin resistance as reflected in HbA1c and triglycerides, with healthier

261 levels in lithium users compared to non-lithium users. Future prospective studies with

262 larger sample sizes will be necessary to confirm whether the association between lithium

263 use and insulin resistance is due to a causal effect of lithium or other factors. A proactive

264 approach to care focused on prevention, early intervention, and consistent monitoring

265 may help prevent long-term health consequences of obesity.

\section{DECLARATIONS}

\section{Ethics approval and consent to participate}

271 The two studies from which data was used for this study were performed in accordance

272 with the Declaration of Helsinki. They received ethics approval by the institutional

273 review boards at the Douglas Mental Health University Institute (Study 1 and 2), McGill

274 University Health Centre (Study 1), and Jewish General Hospital (Study 1). 
277 Not applicable.

279 Availability of data and material

280 The datasets used and/or analysed during the current study are available from the

281 corresponding author on reasonable request.

\section{Competing interests}

284 S.R. receives investigator-initiated grant funding from Satellite Healthcare for an

285 unrelated project. S.B. has received peer-reviewed research funding from Canadian

286 Institutes of Health Research, Pfizer Research Award, National Alliance for Research on

287 Schizophrenia and Depression (NARSAD), and support for knowledge translation and

288 research contracts from Astra-Zeneca, Bristol-Myers-Squibb, Lundbeck, Otsuka,

289 Sunovion; has been a consultant or part of an advisory board for Allergan, Astra Zeneca,

290 Bristol-Myers Squibb (BMS), Forest Laboratories, Janssen-Ortho, Lundbeck, Merck,

291 Otsuka, Pfizer, Sunovion; and part of the speaker bureau for Allergan, Astra Zeneca,

292 BMS, Janssen-Ortho, Lundbeck, Otsuka, Pfizer, Purdue, Sunovion.

$294 \quad$ Funding

295 The findings in this paper used data from projects funded by the Kidney Foundation of

296 Canada, Lady Davis Institute, and charitable donations to the JGH Division of Geriatric

297 Psychiatry. S.J. and O.L. receive salary support from a Fonds de Recherche Québec-

298 Santé (FRQS) Junior Investigator award. 
300 Author's contributions

301 S.R., O.L., J.F.S., and J.P. designed the study; S.R., O.L., J.F.S., H.P. and J.P. analyzed

302 and interpreted the data; S.R.., O.L., J.F.S., H.P. and J.P. drafted and revised the paper;

303 all authors approved the final version of the manuscript and have agreed both to be

304 personally accountable for the author's own contributions and to ensure that questions

305 related to the accuracy or integrity of any part of the work, even ones in which the author

306 was not personally involved, are appropriately investigated, resolved, at the resolution

307 documented in the literature.

308

309 Acknowledgements

310 Not applicable. 
Table 1: Demographics \& Clinical Characteristics in Lithium Users and Non-Users with Bipolar Disorder (BD), $n=129$

\begin{tabular}{|c|c|c|c|}
\hline Variable & Li Users ( $n=66)$ & $\begin{array}{l}\text { Non-Li Users } \\
(n=63)\end{array}$ & Stats \\
\hline $\begin{array}{l}\text { Age (years), [mean } \\
( \pm \mathrm{SD})]\end{array}$ & 49.05 (11.78) & $46.71(11.20)$ & $\begin{array}{l}\mathrm{U}=1850.5 \\
\mathrm{p}=0.281, \mathrm{z}=-1.077\end{array}$ \\
\hline \% Male, $[\%(n=)]$ & $43.94 \%(n=29)$ & $53.96 \%(n=34)$ & $\mathrm{p}=0.043, \mathrm{x}^{2}=0.169$ \\
\hline 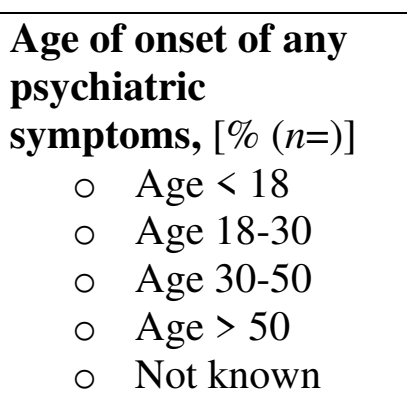 & $\begin{array}{l}33.84 \%(n=22) \\
43.08 \%(n=28) \\
18.46 \%(n=12) \\
4.62 \%(n=3) \\
0.0 \%(n=0)\end{array}$ & $\begin{array}{l}59.68 \%(n=37) \\
24.19 \%(n=15) \\
12.90 \%(n=8) \\
0.0 \%(n=0) \\
3.23 \%(n=2)\end{array}$ & $\mathrm{p}=0.017, \mathrm{x}^{2}=13.8$ \\
\hline $\begin{array}{l}\text { Total number of } \\
\text { previous mood } \\
\text { episodes, }[\%(\mathrm{n}=)] \\
\circ \quad 1 \text { episode } \\
\circ \quad 2 \text { episodes } \\
\circ \quad 3 \text { episodes } \\
\circ \quad>4 \text { episodes }\end{array}$ & $\begin{array}{l}11.67 \%(n=7) \\
10 \%(n=6) \\
8.33 \%(n=5) \\
70 \%(n=45)\end{array}$ & $\begin{array}{l}0 \%(n=0) \\
0 \%(n=0) \\
3.33 \%(n=2) \\
91.67 \%(n=55)\end{array}$ & $\mathrm{p}=0.001, \mathrm{x}^{2}=15.9$ \\
\hline $\begin{array}{l}\text { MADRS score, [mean } \\
( \pm \text { SD })]\end{array}$ & $4.30(4.62)$ & $6.81(6.93)$ & $\begin{array}{l}\mathrm{U}=4922.5, \mathrm{p}=0.045 \\
\mathrm{z}=-2.01\end{array}$ \\
\hline $\begin{array}{l}\text { YMRS score, [mean } \\
( \pm \text { SD })]\end{array}$ & $4.42(8.03)$ & $15.90(12.80)$ & $\begin{array}{l}\mathrm{U}=719, \mathrm{p}=1.57^{\wedge}{ }_{-} \\
12, \mathrm{z}=-7.07\end{array}$ \\
\hline $\begin{array}{l}\text { Number of } \\
\text { psychotropic } \\
\text { medications, } n=126, \\
{[\text { mean }( \pm \mathrm{SD})]}\end{array}$ & $3.13(1.72)$ & $3.40(1.40)$ & $\begin{array}{l}\mathrm{U}=1738, \mathrm{p}=0.280 \\
\mathrm{z}=-1.080\end{array}$ \\
\hline $\begin{array}{l}\text { On } \\
\text { anticonvulsant } \\
\text { s, [n (\%)] }\end{array}$ & $36.5 \%(n=23)$ & $82.5 \%(n=52)$ & $\begin{array}{l}\mathrm{p}=1.414 \mathrm{x} 10-7 \\
\mathrm{x}^{2}=27.70\end{array}$ \\
\hline $\begin{array}{ll}\circ & \text { On } \\
& \text { antidepressants } \\
& ,[\mathrm{n}(\%)]\end{array}$ & $38.1 \%(n=24)$ & $57.1 \%(n=36)$ & $\mathrm{p}=0.032, \mathrm{x}^{2}=4.582$ \\
\hline $\begin{array}{l}\text { On } \\
\text { antipsychotics, } \\
{[\mathrm{n}(\%)]}\end{array}$ & $58.7 \%(n=37)$ & $76.2 \%(n=48)$ & $\mathrm{p}=0.036, \mathrm{x}^{2}=4.375$ \\
\hline
\end{tabular}




\begin{tabular}{|c|l|l|l|}
\hline & & & \\
\hline $\begin{array}{l}\text { Number of non- } \\
\text { psychotropic } \\
\text { medications, [mean } \\
( \pm \text { SD)] } \\
\circ \quad \text { For } \\
\text { hypertension, } \\
\mathrm{n}=117,[\mathrm{n}(\%)]\end{array}$ & $0.67(1.004)$ & $2.37(2.951)$ & $\begin{array}{l}\mathrm{U}=674, \mathrm{p}=0.001, \\
\mathrm{z}=-3.371\end{array}$ \\
$\begin{array}{l}\text { For diabetes, } \\
\mathrm{n}=117,[\mathrm{n}(\%)]\end{array}$ & $7.4 \%(n=4)$ & $22.2 \%(n=14)$ & $\mathrm{p}=0.791, \mathrm{x}^{2}=0.374$ \\
\hline $\begin{array}{l}\text { For } \\
\text { dyslipidemia, } \\
\mathrm{n}=117,[\mathrm{n}(\%)]\end{array}$ & $3.7 \%(n=2)$ & $22.2 \%(n=14)$ & $\mathrm{p}=0.004, \mathrm{x}^{2}=8.447$ \\
\hline$\quad \begin{array}{l}\text { For thyroid, } \mathrm{n}= \\
105,[\mathrm{n}(\%)]\end{array}$ & $18.4 \%(n=9)$ & $23.2 \%(n=13)$ & $\mathrm{p}=0.543, \mathrm{x}^{2}=0.371$ \\
\hline
\end{tabular}


Table 2: Body Mass Index (BMI) and other Physical Health Outcomes in Lithium Users and Non-Users with Bipolar Disorder (BD) $(n=129)$

\begin{tabular}{|c|c|c|c|}
\hline Variable & Li Users $(n=66)$ & $\begin{array}{l}\text { Non-Li Users } \\
(n=63)\end{array}$ & Stats \\
\hline Obesity, [n (\%)] & $42.42 \%(n=28)$ & $34.92 \%(n=22)$ & $\begin{array}{l}\mathrm{p}=0.384 \\
\mathrm{x}^{2}=0.758\end{array}$ \\
\hline $\begin{array}{l}\text { Mean BMI, }\left(\mathrm{kg} / \mathrm{m}^{2}\right) \text { [mean } \\
( \pm \mathrm{SD})]\end{array}$ & $29.10(+/-6.70)$ & $30.20(+/-8.57)$ & $\begin{array}{l}U=2051, \\
p=0.895, z=- \\
0.132\end{array}$ \\
\hline $\begin{array}{cl}\text { BMI stratification, [n (\%)] } \\
\circ & \text { Underweight, <19 } \\
\circ & \text { Normal, 19-25 } \\
\circ & \text { Overweight, 25-30 } \\
\circ & \text { Class I Obesity, 30-35 } \\
\circ & \text { Class II \& III Obesity, } \\
& >35\end{array}$ & $\begin{array}{l}0 \%(n=0) \\
30.30 \%(n=20) \\
27.27 \%(n=18) \\
25.76 \%,(n=17) \\
16.67 \%,(n=11)\end{array}$ & $\begin{array}{l}0,0 \\
33.33 \%,(n=21) \\
31.75 \%,(n=20) \\
11.11 \%,(n=7) \\
23.81 \%,(n=15)\end{array}$ & $\mathrm{p}=0.184, \mathrm{x}^{2}=4.85$ \\
\hline Metabolic Syndrome [n (\%)] & $35.71 \%(n=15)$ & $44.18 \%(n=19)$ & $\mathrm{p}=0.623, \mathrm{x}^{2}=0.24$ \\
\hline $\begin{array}{cl}\text { Waist circumference, NIH } \\
\circ \quad \text { Male, }[\text { mean }( \pm \mathrm{SD})] \\
\circ & \text { Female, }[\text { mean }( \pm \mathrm{SD})]\end{array}$ & $\begin{array}{l}107.91(20.51) \\
98.85(16.28)\end{array}$ & $\begin{array}{l}107.77(16.79) \\
105.97(19.03)\end{array}$ & $\begin{array}{l}U=1906.5 \\
p=0.416, z=- \\
0.813\end{array}$ \\
\hline 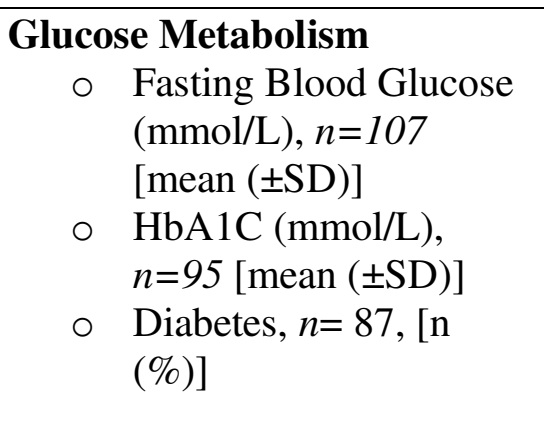 & $\begin{array}{l}5.52(1.03) \\
5.24(0.53) \\
16.67 \%(n=7)\end{array}$ & $6.01(1.83)$ & $\begin{array}{l}U=1344.5, \\
p=0.712, z=- \\
0.369 \\
U=753.5, \\
p=0.006 *, z=- \\
2.76 \\
p=0.088, x^{2}=3.19\end{array}$ \\
\hline $\begin{array}{l}\text { Lipid Profile } \\
\begin{aligned} \text { Total Cholesterol } \\
(\mathrm{mmol} / \mathrm{L}), n=103\end{aligned} \\
{[\text { mean }( \pm \mathrm{SD})]} \\
\circ \quad \mathrm{HDL}(\mathrm{mmol} / \mathrm{L}), \\
n=102,[\mathrm{mean} \\
( \pm \mathrm{SD})] \\
\circ \quad \mathrm{LDL}(\mathrm{mmol} / \mathrm{L}), \\
n=100,[\mathrm{mean} \\
( \pm \mathrm{SD})] \\
\\
\text { Triglycerides }\end{array}$ & $\begin{array}{l}4.72(1.02) \\
1.30(0.33) \\
2.79(0.87) \\
1.46(0.88)\end{array}$ & $\begin{array}{l}1.24(0.37) \\
2.75(0.89) \\
2.01(1.25)\end{array}$ & $\begin{array}{l}U=1233, \\
p=0.582, z=-0.55 \\
U=1084.5, \\
p=0.162, z=-1.40 \\
U=1110, \\
p=0.377, z=- \\
0.883 \\
U=947,\end{array}$ \\
\hline
\end{tabular}




\begin{tabular}{|c|c|c|c|c|}
\hline O & $\begin{array}{l}(\mathrm{mmol} / \mathrm{L}), n=102, \\
{[\text { mean }( \pm \mathrm{SD})]} \\
\text { Dyslipidemia, } \mathrm{n}=96,[\mathrm{n} \\
(\%)]\end{array}$ & $50 \%,(n=23)$ & $70 \%,(n=35)$ & $\begin{array}{l}\mathbf{p}=\mathbf{0 . 0 2 0} *, \mathrm{z}=- \\
2.32 \\
\mathrm{p}=0.06, \mathrm{x}^{2}=4.007\end{array}$ \\
\hline $\begin{array}{r}\text { Hype } \\
0\end{array}$ & $\begin{array}{l}\text { tension } \\
\text { Hypertension, } n=117 \text {, } \\
{[\mathrm{n}(\%)]}\end{array}$ & $12.96 \%,(n=7)$ & $19.05 \%,(n=12)$ & $\begin{array}{l}\mathrm{p}=0.455 \\
\mathrm{x}^{2}=0.791\end{array}$ \\
\hline $\begin{array}{r}\text { Thyr } \\
\circ\end{array}$ & $\begin{array}{l}\text { id Function } \\
\mathrm{TSH}, n=103,[\text { mean } \\
( \pm \mathrm{SD})]\end{array}$ & $2.39(1.26)$ & $2.60(1.43)$ & $\begin{array}{l}\mathrm{U}=1187, \\
\mathrm{p}=0.411, \mathrm{z}=- \\
0.823\end{array}$ \\
\hline O & $\begin{array}{l}\text { Hypothyroidism, } \\
\mathrm{n}=102,[\mathrm{n}(\%)]\end{array}$ & $41.81 \%,(n=23)$ & $59.57 \%,(n=28)$ & $\begin{array}{l}\mathrm{p}=0.112 \\
\mathrm{x}^{2}=3.196\end{array}$ \\
\hline
\end{tabular}

Complete information was available on all participants for BMI and waist circumference. For other domains, the number of patients available is indicated next to the name of each variable $(n=)$. 


\section{References}

1. Yatham LN, Kennedy SH, Parikh SV, et al. Canadian Network for Mood and Anxiety Treatments (CANMAT) and International Society for Bipolar Disorders (ISBD) 2018 guidelines for the management of patients with bipolar disorder. Bipolar Disord. 2018;20(2):97-170.

2. Baldessarini RJ, Tondo L, Hennen J. Lithium treatment and suicide risk in major affective disorders: update and new findings. J Clin Psychiatry. 2003;64 Suppl $5: 44-52$.

3. McKnight RF, Adida M, Budge K, Stockton S, Goodwin GM, Geddes JR. Lithium toxicity profile: a systematic review and meta-analysis. Lancet. 2012;379(9817):721-728.

4. Hayes JF, Marston L, Walters K, Geddes JR, King M, Osborn DP. Adverse Renal, Endocrine, Hepatic, and Metabolic Events during Maintenance Mood Stabilizer Treatment for Bipolar Disorder: A Population-Based Cohort Study. PLoS Med. 2016;13(8):e1002058.

5. Scherk H, Pajonk FG, Leucht S. Second-generation antipsychotic agents in the treatment of acute mania: a systematic review and meta-analysis of randomized controlled trials. Arch Gen Psychiatry. 2007;64(4):442-455.

6. Grundy SM, Cleeman JI, Daniels SR, et al. Diagnosis and management of the metabolic syndrome: an American Heart Association/National Heart, Lung, and Blood Institute Scientific Statement. Circulation. 2005;112(17):2735-2752. 
7. Kemp DE, Sylvia LG, Calabrese JR, et al. General medical burden in bipolar disorder: findings from the LiTMUS comparative effectiveness trial. Acta Psychiatr Scand. 2014;129(1):24-34.

8. Baldessarini RJ, Perry R, Pike J. Factors associated with treatment nonadherence among US bipolar disorder patients. Hum Psychopharmacol. 2008;23(2):95-105.

9. Fagiolini A, Kupfer DJ, Houck PR, Novick DM, Frank E. Obesity as a correlate of outcome in patients with bipolar I disorder. Am J Psychiatry. 2003;160(1):112117.

10. Jin H, McCrone P. Cost-of-illness studies for bipolar disorder: systematic review of international studies. Pharmacoeconomics. 2015;33(4):341-353.

11. National Collaborating Centre for Mental H. National Institute for Health and Care Excellence: Clinical Guidelines. In: Bipolar Disorder: The NICE Guideline on the Assessment and Management of Bipolar Disorder in Adults, Children and Young People in Primary and Secondary Care. London: The British Psychological Society and The Royal College of Psychiatrists

12. McElroy SL, Keck PE, Jr. Obesity in bipolar disorder: an overview. Curr Psychiatry Rep. 2012;14(6):650-658.

13. de Almeida KM, Moreira CL, Lafer B. Metabolic syndrome and bipolar disorder: what should psychiatrists know? CNS Neurosci Ther. 2012;18(2):160-166.

14. Bowden CL, Mosolov S, Hranov L, et al. Efficacy of valproate versus lithium in mania or mixed mania: a randomized, open 12-week trial. Int Clin Psychopharmacol. 2010;25(2):60-67. 
15. Ackerman S, Nolan LJ. Bodyweight Gain Induced by Psychotropic Drugs. CNS Drugs. 1998;9(2):135-151.

16. Bowden CL, Grunze H, Mullen J, et al. A randomized, double-blind, placebocontrolled efficacy and safety study of quetiapine or lithium as monotherapy for mania in bipolar disorder. J Clin Psychiatry. 2005;66(1):111-121.

17. Fotso Soh J, Torres-Platas SG, Beaulieu S, et al. Atorvastatin in the treatment of Lithium-induced nephrogenic diabetes insipidus: the protocol of a randomized controlled trial. BMC Psychiatry. 2018;18(1):227.

18. Kanagarajan K, Gou K, Antinora C, et al. Morningness-Eveningness questionnaire in bipolar disorder. Psychiatry Res. 2018;262:102-107.

19. Montgomery SA, Asberg M. A new depression scale designed to be sensitive to change. Br J Psychiatry. 1979;134:382-389.

20. Young RC, Biggs JT, Ziegler VE, Meyer DA. A rating scale for mania: reliability, validity and sensitivity. Br J Psychiatry. 1978;133:429-435.

21. Vincenzi B, Greene CM, Ulloa M, Parnarouskis L, Jackson JW, Henderson DC. Lithium or Valproate Adjunctive Therapy to Second-generation Antipsychotics and Metabolic Variables in Patients With Schizophrenia or Schizoaffective Disorder. J Psychiatr Pract. 2016;22(3):175-182.

22. Calkin CV, Ruzickova M, Uher R, et al. Insulin resistance and outcome in bipolar disorder. Br J Psychiatry. 2015;206(1):52-57.

23. Steardo L, Jr., Fabrazzo M, Sampogna G, et al. Impaired glucose metabolism in bipolar patients and response to mood stabilizer treatments. J Affect Disord. 2019;245:174-179. 
24. McIntyre RS, Danilewitz M, Liauw SS, et al. Bipolar disorder and metabolic syndrome: an international perspective. J Affect Disord. 2010;126(3):366-387.

25. Kaidanovich O, Eldar-Finkelman $\mathrm{H}$. The role of glycogen synthase kinase-3 in insulin resistance and type 2 diabetes. Expert Opin Ther Targets. 2002;6(5):555561.

26. Williams RS, Cheng L, Mudge AW, Harwood AJ. A common mechanism of action for three mood-stabilizing drugs. Nature. 2002;417(6886):292-295.

27. Melo MCA, Abreu RLC, Linhares Neto VB, de Bruin PFC, de Bruin VMS. Chronotype and circadian rhythm in bipolar disorder: A systematic review. Sleep Medicine Reviews. 2017;34:46-58.

28. McGuire S. Shields M., Carroll M.D., Ogden C.L. adult obesity prevalence in Canada and the United States. NCHS data brief no. 56, Hyattsville, MD: National Center for Health Statistics, 2011. Adv Nutr. 2011;2(4):368-369.

29. Lamontagne P, Hamel D. Surveillance du statut pondéral chez les adultes québécois: Portrait et évolution de 1987 à 2010. Direction de l'analyse et de l'évaluation des systèmes de soins et services ...; 2012.

30. Riediger ND, Clara I. Prevalence of metabolic syndrome in the Canadian adult population [published correction appears in CMAJ. $2019 \mathrm{Feb}$ 4;191(5):E141]. CMAJ. 2011;183(15):E1127-E1134. doi:10.1503/cmaj.110070

31. Tully A, Murphy E, Smyth S, et al. Interventions for the management of obesity in people with bipolar disorder. Cochrane Database Syst Rev. 2018;2018(4):CD013006. 
32. Krakauer NY, Krakauer JC. A New Body Shape Index Predicts Mortality Hazard Independently of Body Mass Index. PLOS ONE. 2012;7(7):e39504.

33. Romero-Corral A, Montori VM, Somers VK, et al. Association of bodyweight with total mortality and with cardiovascular events in coronary artery disease: a systematic review of cohort studies. Lancet. 2006;368(9536):666-678. 